\title{
Effect of Moringa oleifera on Germination and Growth of Triticum aestivum
}

\author{
Noor Shaila Sarmin \\ Dept. of Agroforestry and Environment, Bangabandhu Sheikh Mujibur Rahman Agricultural \\ University, Gazipur, Bangladesh
}

Corresponding author: noorshaila01@ gmail.com

\begin{abstract}
The study was undertaken to find out the interaction among Moringa oleifera, a perennial medicinal tree and Wheat (Triticum aestivum). Five different concentrations $(0 \%$ i.e. fresh water, $25 \%, 50 \%, 75 \%$ and $100 \%$ ) for each of Moringa leaf, bark and root extracts were used to examine the effects on germination and growth of Triticum. Germination percent and plumule length was reduced compared to control. Bark extract concentration of $25 \%$ produced longest hypocotyls $(58 \mathrm{~mm})$ and flag leaf $(17.28 \mathrm{~cm})$; and $50 \%$ produced longest $(60.75 \mathrm{~cm})$ plant. Highest soil plant analytical development (SPAD) value (60) was recorded in 50\% concentration of leaf extract applied plant. Triticum tiller number was positively affected by 50\%, 100\% leaf and 50\% bark extracts. Soil moisture percent was increased with extract application. Longest $(11.08 \mathrm{~cm})$ and shortest $(9.5 \mathrm{~cm})$ spike was recorded on 75\% bark and 25\% root extract application. All concentrations of leaf and root extract shown negative result for root and shoot weight. Maximum and minimum Triticum grain weight was recorded at 50\% Moringa bark and 50\% Moringa leaf extract, respectively.
\end{abstract}

Key words: Moringa oleifera, Triticum aestivum, leaf extract, bark extract and root extract

\section{Introduction}

Moringa oleifera is an important vegetable in many tropical and sub-tropical countries including Bangladesh. Its annual production is comparatively higher than many other secondary vegetables. Most of the parts of M. oleifera have medicinal value. Leaves, flowers and unripe fruits are used as vegetables, and roots and barks are used for medicinal purpose (Anwar et al. 2007). The flowers, leaves and roots are used for the treatment of ascites, rheumatism and venomous bites and as a cardiac and circulatory stimulant in some folk cures. The root bark and the roots of young tree are rubefacient and vesicant (Hartwell, 1995). More than 300 diseases including cancer, diabetes and high blood pressure can be controlled or cured by M. oleifera (Anon. 2009). M. oleifera seeds are used for purifying water in some African countries (Suarez et al. 2003).

All kinds of nutrient and amino acids needed for human body are available in $M$. oleifera, so this tree is also called "Miracle tree". Moringa contains protein, fibre, calcium, phosphorus, potassium, sulfur, iron, ascorbic acid, carotene, choline, thiamine, riboflavin, nicotinic acid, and a complete amino acid profile in a sufficient amount (Bau et al. 1994). Its fresh leaves contain $19.3 \% 26.4 \%$ crude protein (Aregheore, 2002) which are essential for livestock and can be used to solve worldwide malnutrition or undernourishment problems (Thurber and Fahey, 2009). The high proportion of minerals and vitamins in Moringa suggest its importance for both human beings and animals. In M. oleifera leaves, there are seven times more vitamin $\mathrm{C}$ than orange, 4 times more calcium and 2 times more protein than milk, and 3 times more potassium than banana, 3 times more iron than Indian spinach and 4 times more vitamins than carrot (Anon. 2010; Hossain et al. 2012). M. oleifera roots are important agents for healing and nourishment. Moringa roots are used to prepare different medicines, perfumes, 
natural pesticides and fertilizers, for cleaning agents, animal fodder and many other important products. The roots are used to treat a variety of illnesses for its antibiotic properties (Fahey, 2005).

Wheat (Triticum aestivum, family Poaceae) was one of the first domesticated food crops and the basic staple food of the majority of the population in many regions of the world. Today, wheat is grown on more land area than any other commercial crop and continues to be the most important food grain source for humans. The population pressure in wheat-consuming countries required more attention be directed towards new approaches to sustainable wheat production by improving both crop quality and yield. Yield improvement must be sought through agronomic approaches that are environmentally safe (Olofsdotter et. al. 1997).

Moringa is widely naturalised in the tropical and subtropical regions including Bangladesh (ICRAF 2001, Duke 1983). In Bangladesh Moringa is an important homestead species and grown sporadically through the roadside of the northwestern region. Moringa may propagate through seed or cutting and germination percent is very high (ICRAF 2001). It requires very little care and it is a drought tolerant species. Moringa is a fast growing species with light crown. Its soft and deciduous leaflets may easily detach, decompose and release nutrients to the under-storey crops. There is a great potential of growing Moringa tree as an important multipurpose species in the cropland agroforestry system situated above the flood level where wheat is also a major cereal crop. Many works (Al-kharusi et al., 2009, Anwar et al., 2007, Guo et al., 2010, Price, 2000, and Fahey, 2005) has been conducted to evaluate the medicinal value of Moringa but still now the interaction effect of different plant parts of Moring $a$ with wheat crop is very limited. So, the study was undertaken to find out the interaction level among Moringa oleifera and Triticum aestivum.

\section{Materials and Method}

This experiment was conducted at the Agroforestry and Environment Department of the Bangabandhu Sheikh Mujibur Rahman Agricultural University, Bangladesh during December 2012 to March 2013.

Collection and preparation of extracts: Fresh leaf, bark and root were collected directly from mature tree. The sample cleaned with tap water by rinsing bath in distilled water, dried by shaking vigorously with hand. The leaves were air dried in shade place. After drying the leaves grinded by an electrical grinder and made powder. The powder was weighed and mixed with distilled water at a ratio of 1:10 (w/v). Then the Mixture was shaken for four hours by an electrical stirrer. The mixture kept in dark at room temperature for 24 hrs. Afterwards, it filtrated through Whatman No. 1 paper. The extracts served as the stock solutions (100\%) for each plant part (leaf, bark and root). For different concentrations, the extracts was diluted as follows: control or $0 \%$ extract (only distilled water), $25 \%$ dilution ( $25 \mathrm{ml}$ extract: $75 \mathrm{ml}$ water), $50 \%$ dilution (50:50 extract: water), $75 \%$ (75 ml extract: $25 \mathrm{ml}$ water), and $100 \%$ dilution (pure extract).

Experimental design and treatment: Experiment was laid out in a Completely Randomized Design (CRD) with four replications. Moringa leaf, bark and root each of $0 \%$ (control), 25\%, 50\%, 75\% and $100 \%$ were used as treatment.

Germination test for the first Experiment: Sterilized petri-dishes $(150 \times 20 \mathrm{~mm}$ diameter $)$ were used for germination test. Three layers of sterilized Whatman No. 1 filter papers were placed in petri dishes and saturated with required extracts of each concentration, while in case of control, only distilled water was used. Fifty sterilized seeds of wheat were placed in each petri-dish and sealed off with foil paper. Petri-dishes then placed in to seed germinator for 8 days and maintained controlled temperature and humidity.

Plant growth in earthen pot: 60 earthen pots were prepared by mixing soil and cowdung (minimum 3 months old) in a ratio of 3:1 and pulverized fairly and then sun dried. Each pot contained $3 \mathrm{~kg}$ of soil. Seeds of wheat (Triticum aestivum var. Prodip) were sterilized with Vitavex and sown directly 
into the pots at a depth of $1.5 \mathrm{~cm}$. Four seeds were planted per pot. The plants were thinned to two plants per pot. All pots were kept weed free.

Seven days after sowing (DAS) different tested plants irrigated at every alternate day with the prepared extracts of different concentrations (control, 25\%, 50\%, 75\% dilutions and 100\% dilution). Subsequent spraying continued during the whole study period.

\section{Results and Discussion}

Germination test: Germination was recorded after eight days. The highest germination rate $(94.5 \%)$ was noted in control $(0 \%)$ treatment followed by $50 \%$ for all the plant extracts (Figure 01). Seed germination rate, was decreased with the increasing concentrations of root extract and the lowest germination rate $(48 \%)$ was observed in the highest concentration i.e. $100 \%$ aqueous extract solution treatment.

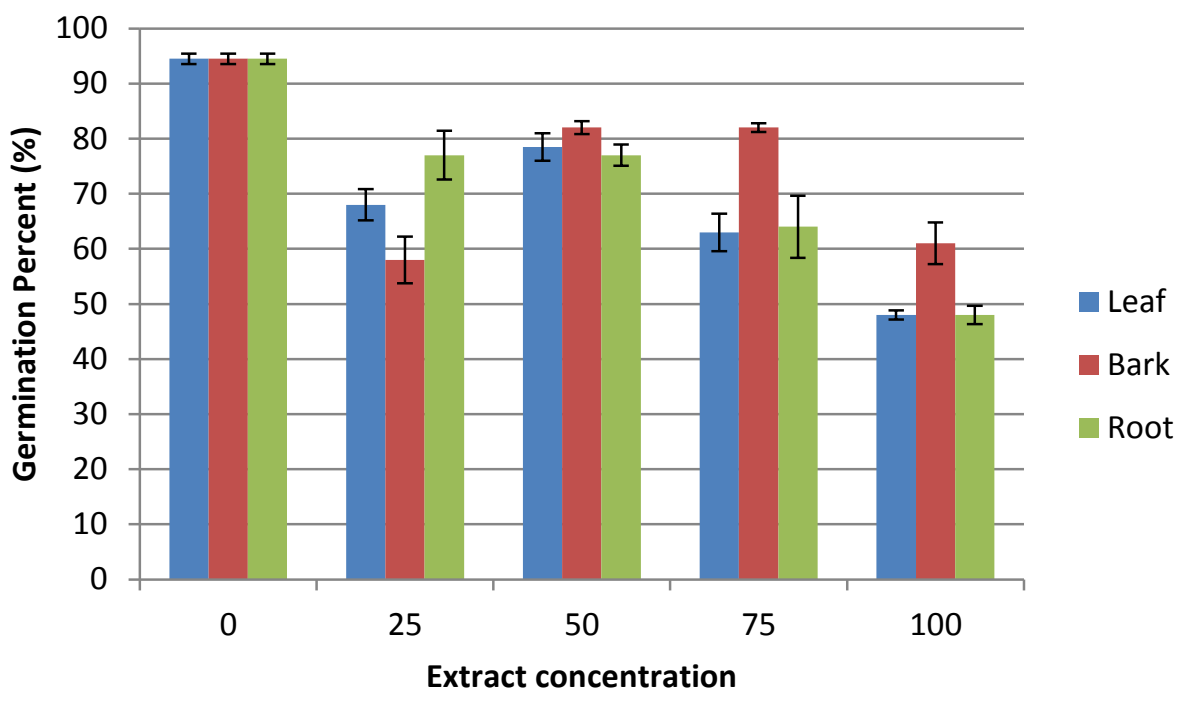

Figure 01. Effect of M. oleifera plant extract on seed germination of Wheat

Hypocotyl and radicle length: For all the extracts longest hypocotyl $(58 \mathrm{~mm})$ was recorded in $25 \%$ concentration followed by control and 50\% concentrations, though 50\% bark extract produced longer hypocotyl than the control. From $25 \%$ to $100 \%$, hypocotyl length was decreased with the increasing concentration for all the treatment and smallest was recorded from $100 \%$ concentration (Figure 02). Like hypocotyls, radicle length was also reduced with the increasing concentrations for leaf and root extracts. Hence the longest $(47.63 \mathrm{~mm})$ and smallest radicle was recorded from control and $100 \%$ concentrations respectively. The shortest radicle for bark extract was noted in 50\% and above this radicle was increased again. Leaf extracts affect more than bark and root extracts (Figure 03). $M$. oleifera leaf extracts contained substances with inhibitory effect which could have lowered germination percent of wheat. Sanker and Rai (1993); and Zakaria and Razak, (1990) also reported that $M$. oleifera leaf extracts contained substances with inhibitory effect which could have lowered germination percentage of rice. Phiri (2010) reported that $M$. oleifera leaf extracts reduced ( $p>0.001$ ) germination percentage of rice by $7 \%$.

$25 \%$ concentration of all extracts and 50\% bark extract shown positive influence on hypocotyl length but the radical length was negatively affected with all the extracts. Phiri (2010) reported that $M$. oleifera leaf extracts increased hypocotyls length of wheat by $14.9 \%$ and reduced radicle length of rice by $28.6 \%$. Phiri and Mbewe (2009) also reported M. oleifera leaf extracts delayed germination and reduced radicle length of common beans. 


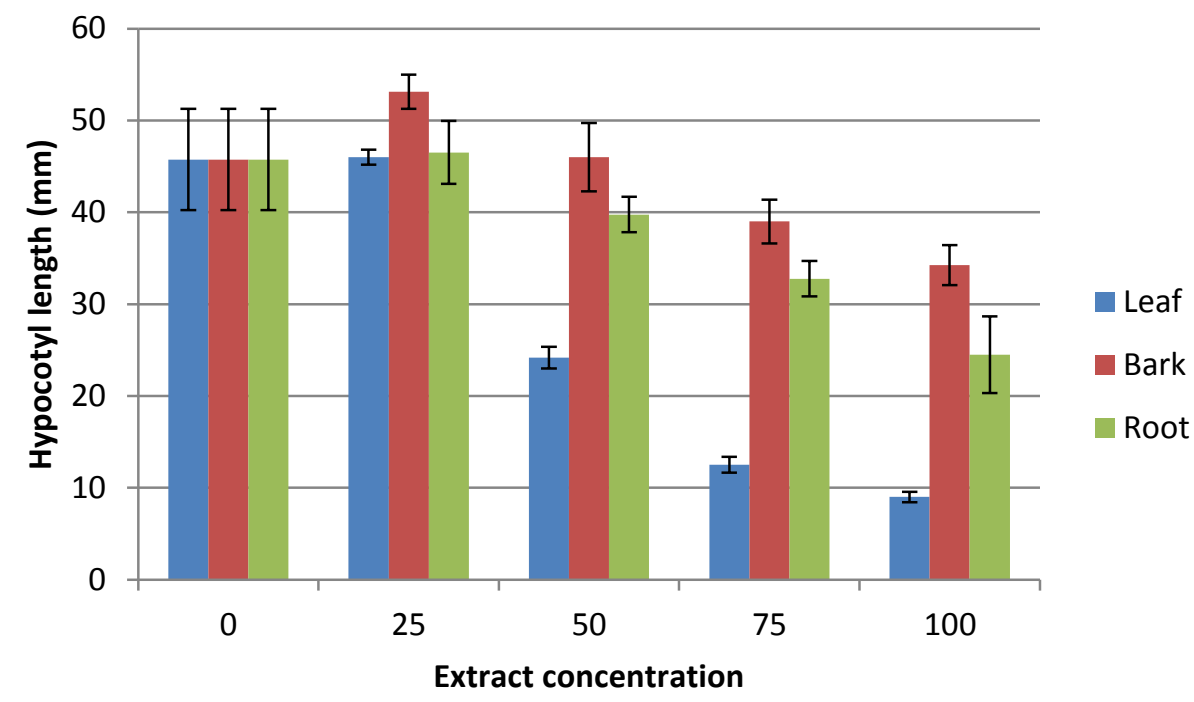

Figure 02. Effect of $M$. oleifera plant extract on hypocotyl length ( $\mathrm{mm})$ of Wheat

Plant height: Effect of different concentrations of M. oleifera leaf, bark and root aqueous extracts on the plant height of wheat at 90 DAS is shown in Figure 04. Among the treated different leaf aqueous extracts, the longest wheat plant $(59.88 \mathrm{~cm})$ was recorded at $25 \%$ concentration followed by $0 \%$ or control $(56.25 \mathrm{~cm})$ and smallest plant recorded at $100 \%$ concentration. However, $50 \%$ and $75 \%$ extract concentrations produced almost similar plant height. When bark extracts was treated, the longest plant $(60.75 \mathrm{~cm})$ was recorded at $50 \%$ concentration followed by the control. The smallest plant was recorded at $25 \%$ concentration. Similar plant height was recorded for control, $75 \%$ and $100 \%$ root extract treatment. The smallest plant was recorded at $25 \%$ concentration. Plant height was less affected by different extracts. Bark extract at $50 \%$ conc. Produced longest plant. Culver et al. (2012) worked on tomato crop and reported that Moringa leaf extract increased plant height by 53\%, $90 \%$ and 149\% when extract was applied once at 2 weeks, both 2 and 4 weeks and every 2 weeks, respectively. El Awady (2003) pointed out that Moringa leaves have high zeatin content. Zeatin is a plant growth hormone from the cytokinines group. It plays an important role in cell division and cell elongation (Taiz and Zeiger 2006) thus influence to the improvements in crop growth and yield (Price 1985). This finding has also been supported by Fuglie (2000) who reported that Moringa accelerate growth of young plants, strengthen plants, increase number of roots, improve resistance to pests and diseases, produce more and larger fruits and generally increase yield by 20 to $35 \%$.

Flag leaf length: Different concentrations of root extracts compared with control showed negative effect on flag leaf length (Figure 05). When bark extracts were applied, 25\% concentration produced longest flag leaf followed by 50\% and $0 \%$ (control). From 25\% concentration of bark extract gradually reduced the flag leaf length while increasing extract concentrations and thus $100 \%$ extract produced smallest flag leaf. When leaf extract applied, 25\% extract produced longest flag leaf followed by control. However other three concentrations (50,75 and 100\%) produced more or less similar flag leaf.

Tiller number: Tiller number was similar when treated with 0,50 and 100\% leaf extract. $25 \%$ extract shown lowest tiller number. Except control, leaf extracts shown highest tiller number followed by bark. However all the concentrations of root extracts shown negative effect over control (Figure 07). 


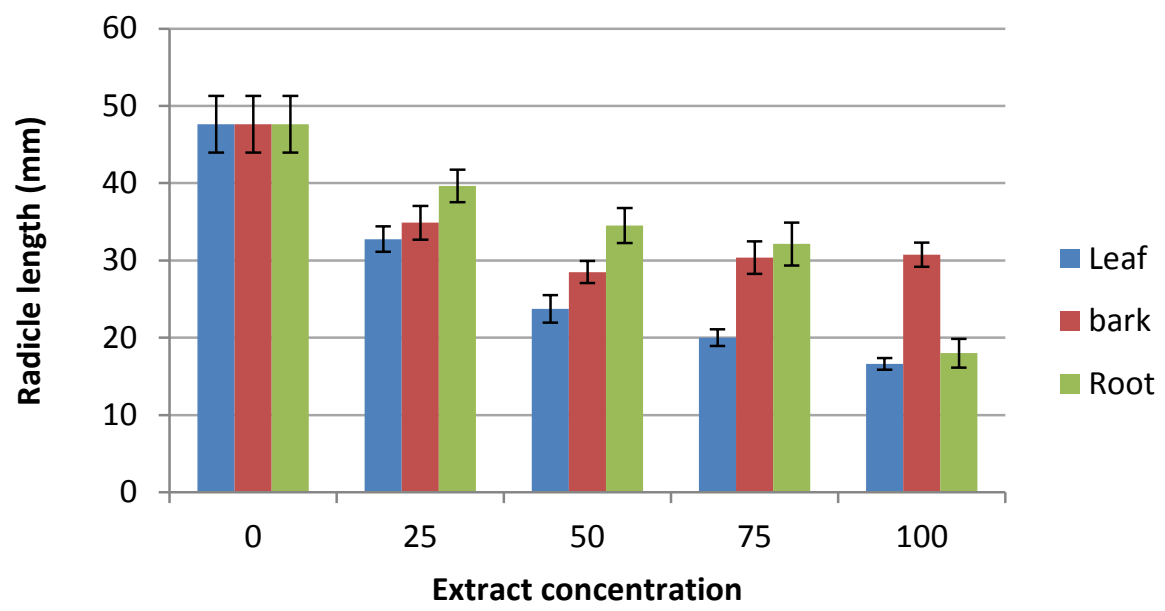

Figure 03. Effect of M. oleifera plant extract on radicle length (mm) of Wheat

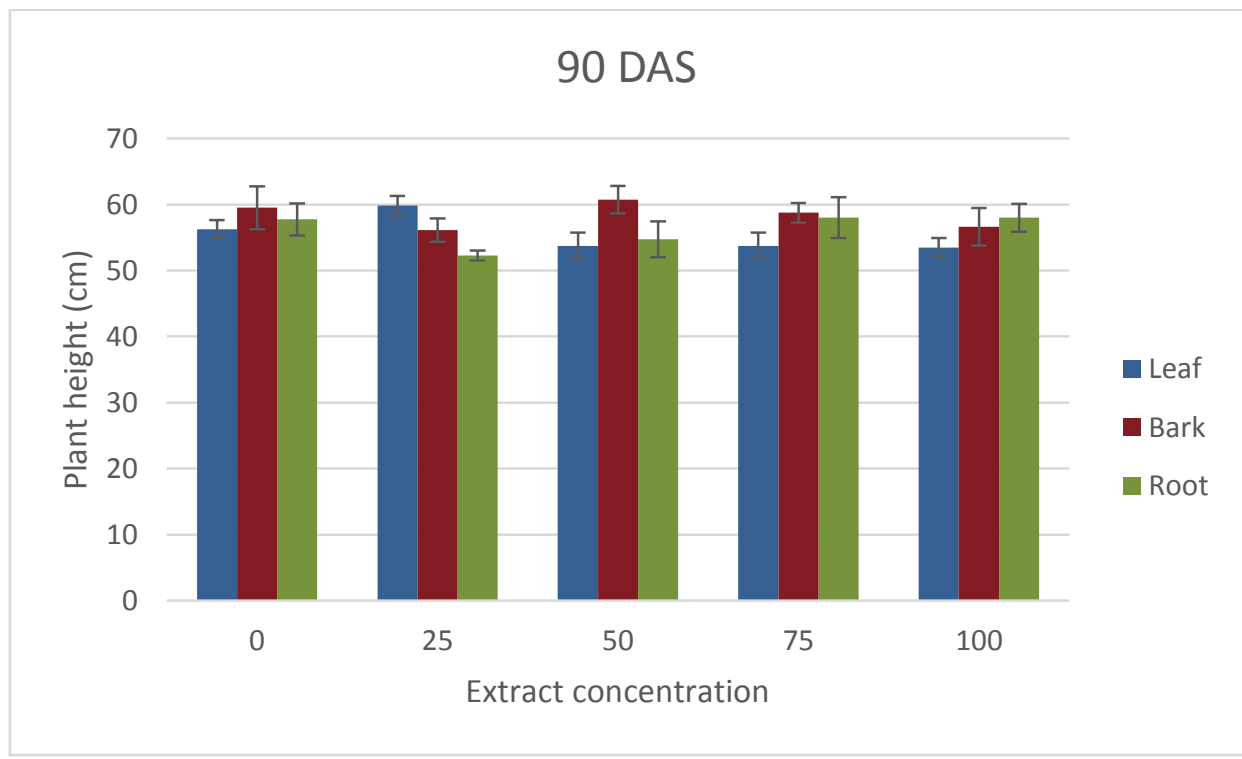

Figure 04. Plant height of Wheat at 90 days after sowing (DAS)

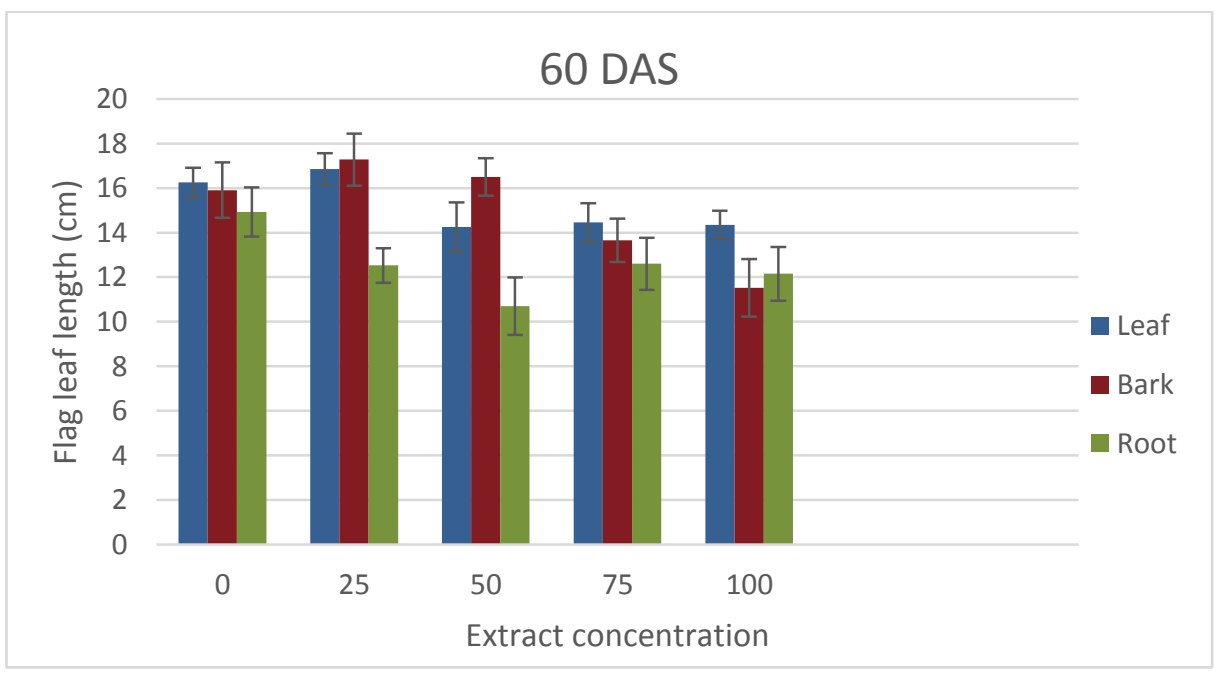

Figure 05. Flag leaf of Wheat at 60 DAS 


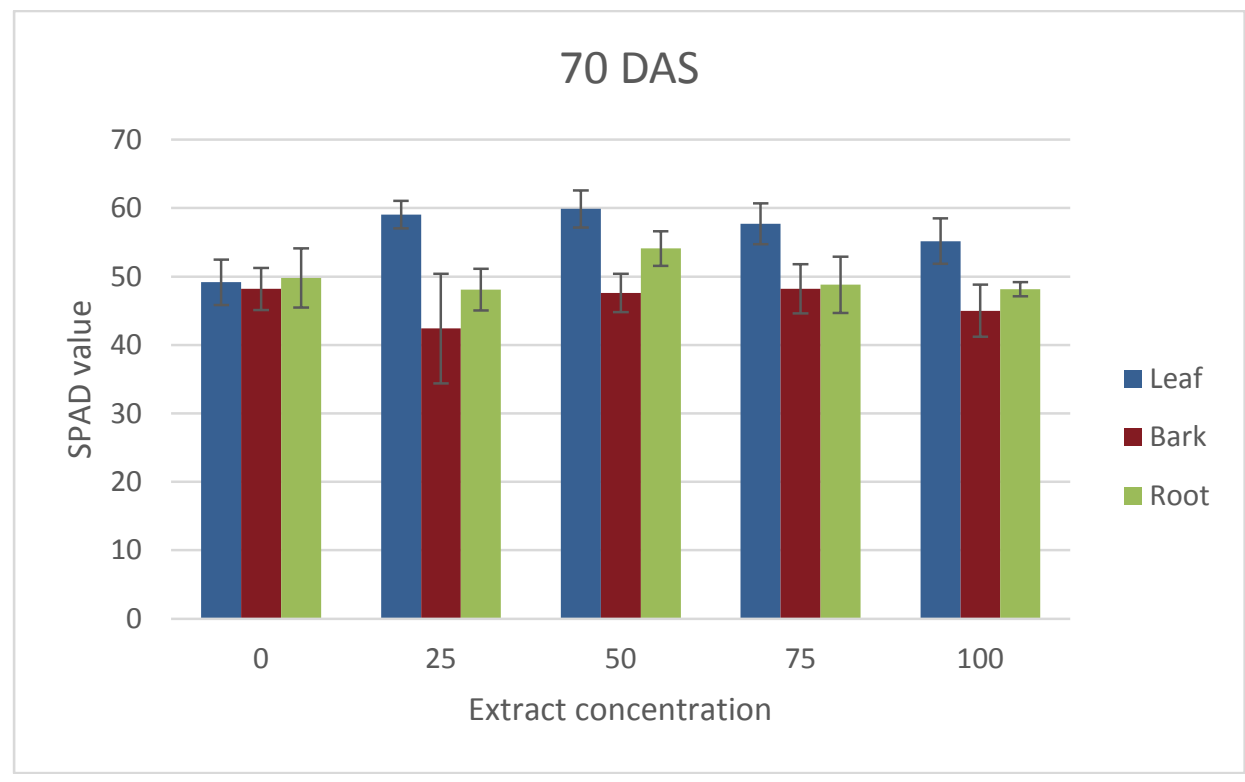

Figure 06. Soil plant analytical development (SPAD) value of Wheat at 60 DAS

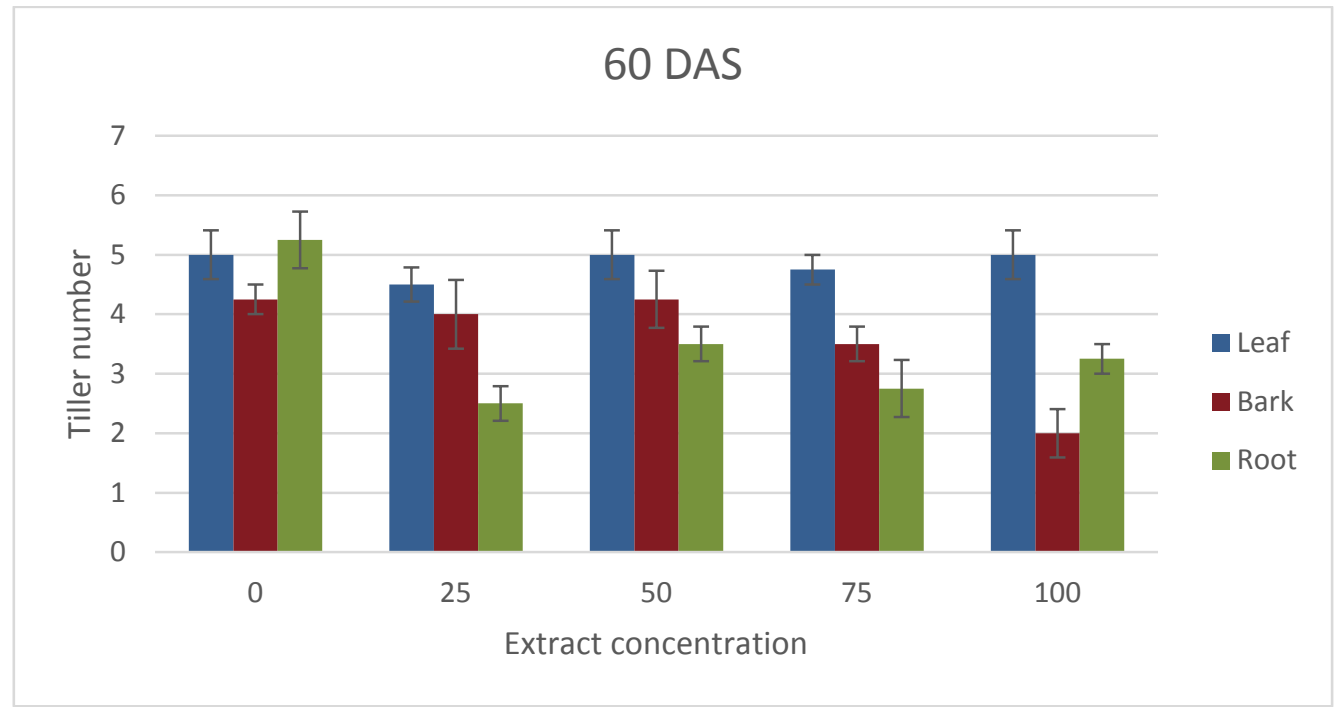

Figure 07. Tiller number of Wheat at 60 DAS

Soil moisture content: Soil moisture content was recorded at 60 DAS. All the pot soils treated with different concentrations of leaf, bark and root shown positive response over control. $25 \%$ bark extract treated soils shown highest moisture content. Moisture content was increased with increasing concentrations (Figure 08). The moisture content of the soil treated with 25, 50, 75 and 100\% aqueous extracts were $7.83 \%, 8.81 \%, 22.31 \%$ and $24.85 \%$ higher over control for leaf, $18.38 \%, 7.99 \%$, $14.84 \%$ and $22.83 \%$ higher over control for bark and $13.18 \%, 17.70 \%, 19.73 \%$ and $21.99 \%$ higher over control for root, respectively. The reason of higher moisture content of the soil treated with different extracts over control may be due to the presence of extracts. Therefore, M. oleifera may be used as mulch. At the same time it adds nutrients to the soil. Davis (2000) reported use of Moringa as green manure significantly improves soil fertility, which indirectly accelerate plant growth and yield. 


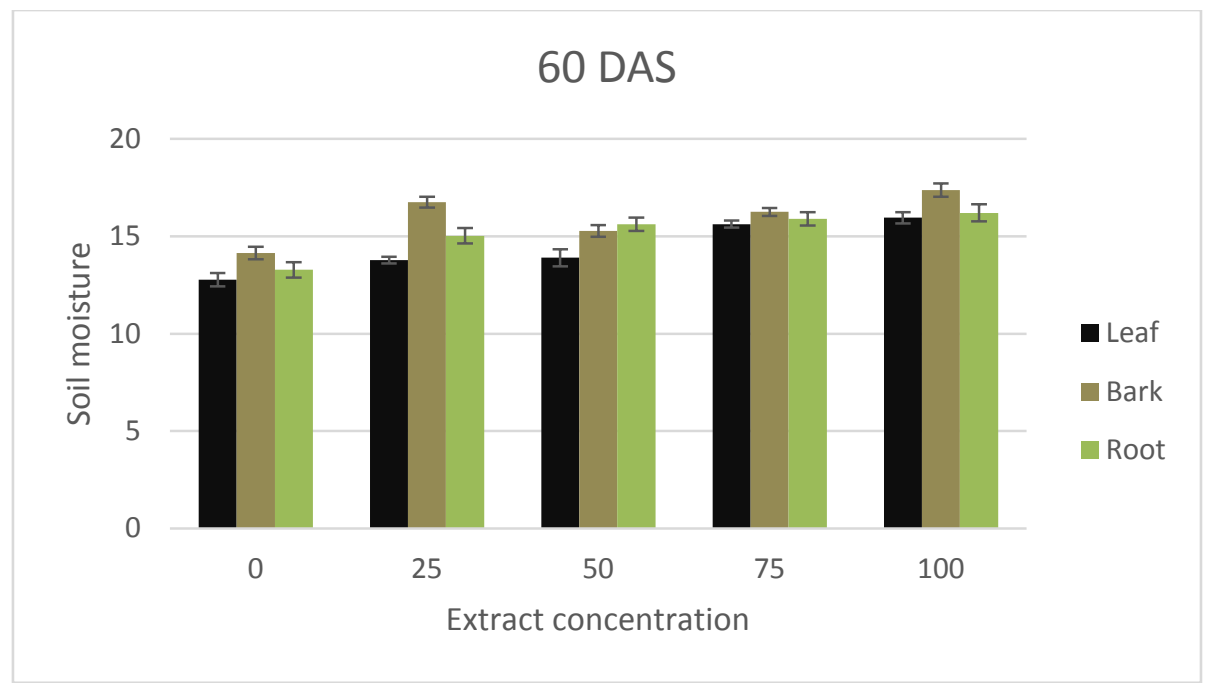

Figure 08. Soil moisture content of Wheat at 60 DAS

Spike length: Up to $75 \%$ concentration leaf and bark extracts shown inverse effect on spike length. Leaf extracts reduced spike length while bark extract increased the spike length. At $100 \%$ concentration bark produced smallest spike (Figure 09). When root extract applied 75\% and 100\% produced similar spike length with the control. However other two concentrations of root extracts produced shorter spikes.

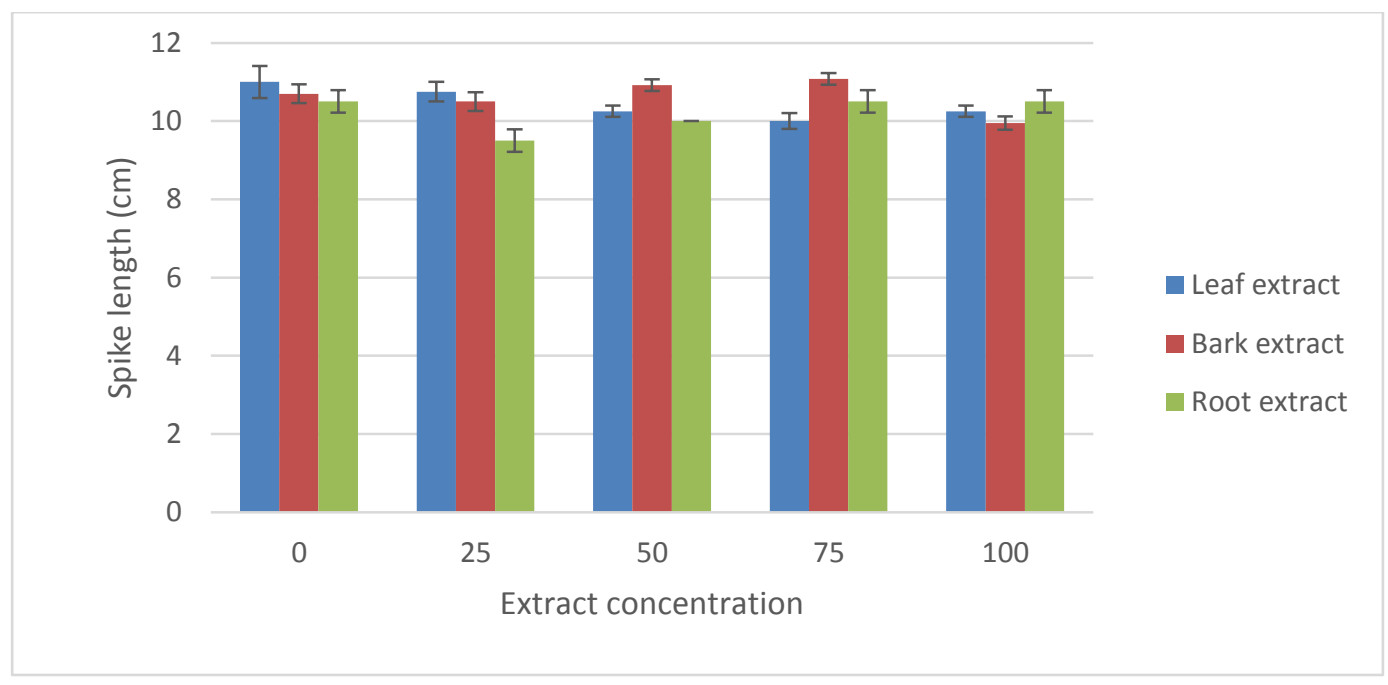

Figure 09 . Spike length $(\mathrm{cm})$ of Wheat at 60 DAS

Shoot weight: In case of shoot weight, leaf and bark extract up to $75 \%$ concentration shown same trend as shown in case of spike length. But $100 \%$ bark extract produced lowest shoot weight (Figure 10). While shoot weight again increased in case of leaf extract. However all the concentrations of root extracts shown negative effect over control. 


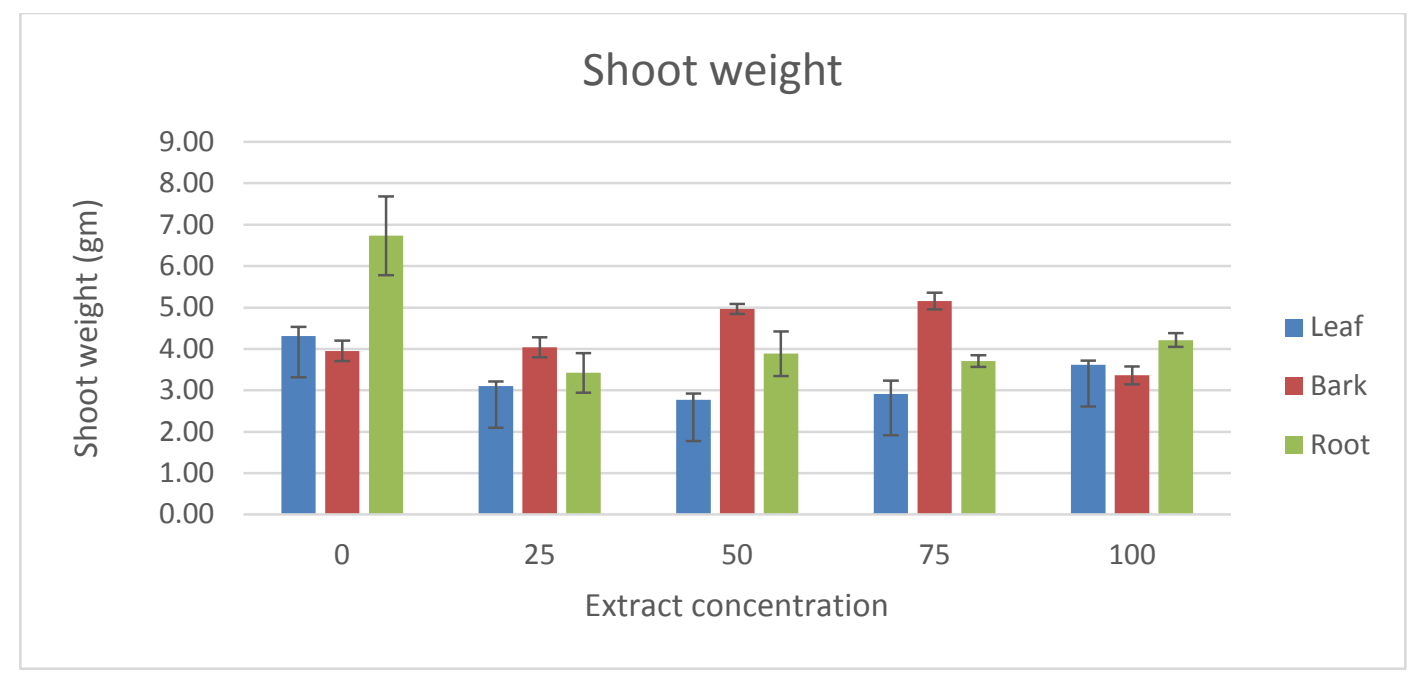

Figure 10. Shoot weight (gm) of Wheat at 60 DAS

Root weight: In case of root weight, all the concentrations of leaf and root extracts shown negative effects over control. When bark extract applied, highest and lowest root weight was recorded from $75 \%$ and $100 \%$ extract treated plants (Figure 11). However from 25 to $75 \%$ concentrations, bark and root extracts gradually increased root weight of wheat.

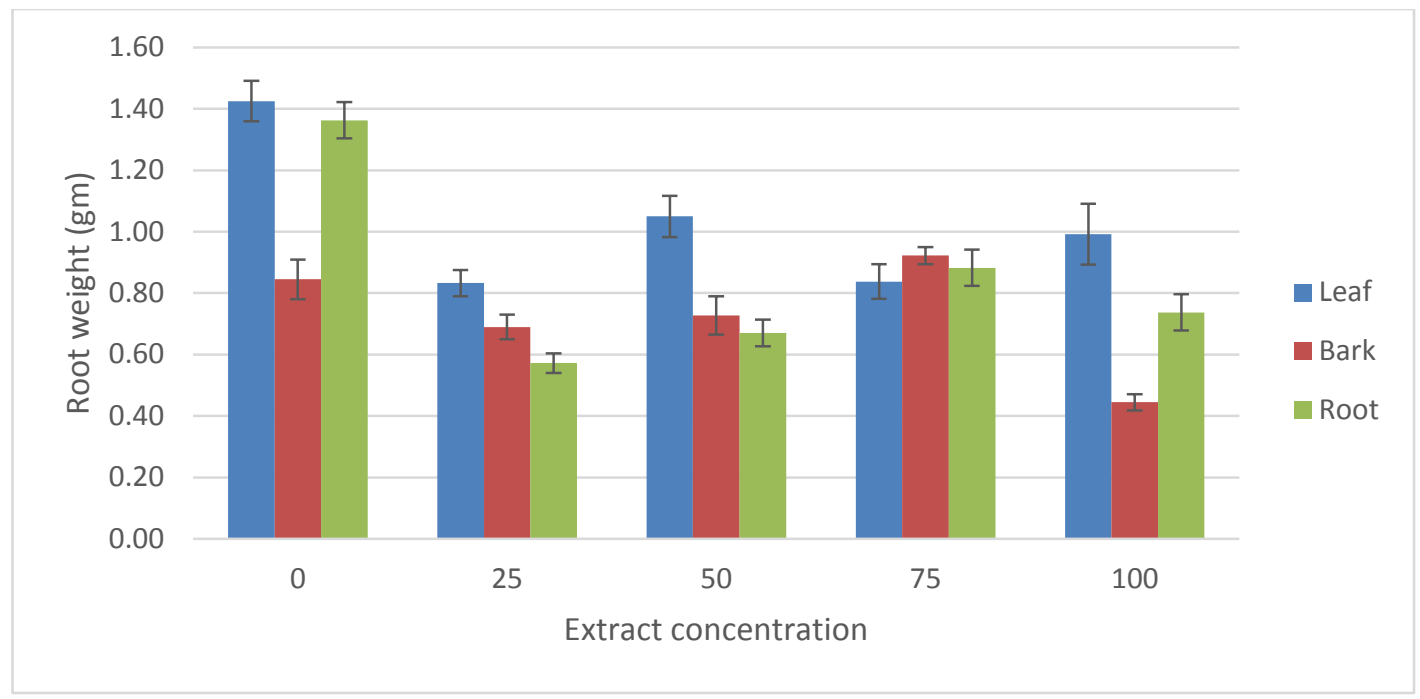

Figure 11. Effect of M. oleifera plant extract on root weight (gm) of Wheat at 60 DAS

Number of grain per spike: Highest number of grain per spike was recorded from 50\% concentration of bark extract followed by $75 \%$ concentration (Figure 12). Spike containing minimum grain was recorded at 50\% leaf extract. Application of root extract increased the number of grain per spike with the increased of extract concentration. Therefore, highest and lowest number of grain per spike recorded at 100\% and $0 \%$ (control) concentrations, respectively. 


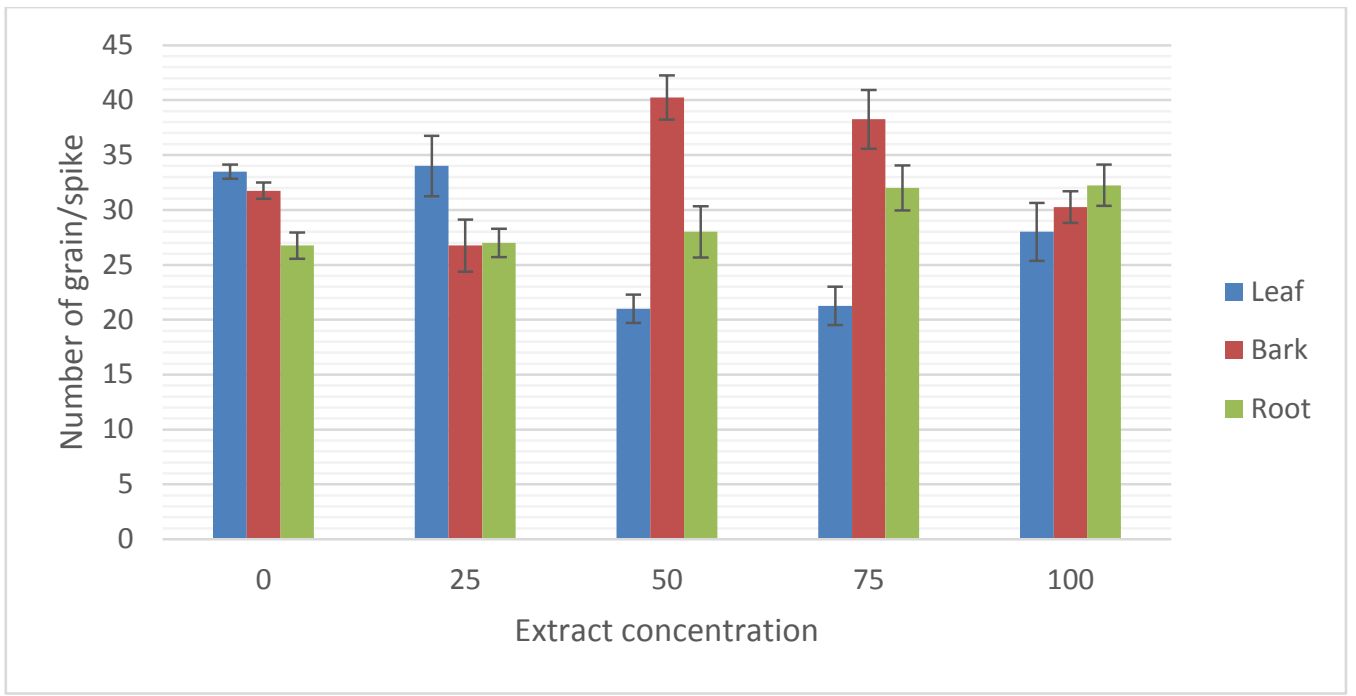

Figure 12. Effect of M. oleifera plant extract on number of grain per spike of Wheat

\section{Conclusion}

Moringa oleifera bark, leaf and root extracts affected differently the germination, growth and yield of wheat plant. Germination rate was decreased for all concentrations of plant extracts compared to control. For all extracts longest hypocotyl was recorded in $25 \%$ concentration followed by control and $50 \%$ concentrations, though 50\% bark extract produced longer hypocotyl than the control. Radicle length was reduced with the increasing concentrations for leaf and root extracts. Hence, longest (47.63 $\mathrm{mm})$ and smallest radicle was recorded from control and $100 \%$ concentrations respectively. Shortest radicle for bark extract was noted in 50\% and above this, radicle was again increased. Leaf extract increased the SPAD value. Plant height, tiller number and spike length was less affected by leaf extract. However, shoot weight and number of grain/spike was severely affected at $50 \%$ concentration of leaf extract. Bark extract increased spike length, shoot weight, root weight, number of grain/spike upto $75 \%$ concentrations. But flag leaf length and tiller number were decreased with increasing concentration of bark extracts. Growth and yield parameters suffered more in root extracts except spike length and number of grain per spike.

\section{Acknowledgement}

Author is grateful to the Research Management Committee (RMC) of Bangabandhu Sheikh Mujibur Rahman Agricultural University, Bangladesh for funding and support during this experiment.

\section{References}

Al-Kharusi, L.M., Elmardi, M.O., Ali A., Al-Said F.A.J., Abdelbasit, K.M. \& Al-Rawahi, S. (2009). Effect of mineral and organic fertilizers on the chemical characteristics and quality of date fruits. Int. J. Agric Biol. 11, 290-296.

Anonymous. (2009). http://www.mathaba.com/moringa-oleifera-the-miracle-tree.html Anonymous. (2010). http://e-articles.info/e/a/title/Moringa-oleifera-::-The-Miracle-Tree

Anwar, F., Latif, S., Ashraf, M. \& Gilani, A.H. (2007). Moringa oleifera: A food plant with multiple medicinal uses. Phytotherapy Research 21, 17-25.

Aregheore, E.M. (2002). Intake and digestibility of Moringa oleifera- batiki grass mixtures by growing goats. Small Ruminant Research 46, 23-28 
Bau, H.M., Villaume, C., Lin, C. F., Evrard, J., Quemener, B., Nicolas, J. P. \& Mejean, L. (1994). Effect of a solid-state fermentation using Rhizopus oligosporus sp. T-3 on elimination of antinutritional substances and modification of biochemical constituents of defatted rapeseed meal. Journal of the Science of food and Agriculture 65, 315-322.

Culver, M., Fanuel, T. \& Chiteka, A. Z. (2012). Effect of Moringa extract on Growth and Yield of Tomato. Greener Journal of Agricultural Sciences 2(5): 207-211.

Davis, K. (2000). The Moringa Tree. (Revised edition). ECHO, 17391 Durrance Rd., North Ft Myers FL 33917, USA.

Duke, JA (1983). Moringa oleifera Lam. Handbook of Energy Crops. <http://www.hort.purdue.edu/newcrop/duke_energy/Moringa_oleifera.html>.

El Awady, A. (2003). Bachelor Thesis. Faculty of Medicine, Cairo University, Cairo, Egypt.

Fahey J.W. (2005). Moringa oleifera: A review of the Medical evidence for its nutritional, Therapeutic and prophylactic properties. Part 1. http://www.TFLjournal.org/article.php /20051201124931586. accessed 15/03/2010.

Fuglie, L. J. (2000). The Miracle Tree: Moringa oleifera: Natural Nutrition for the Tropics. The Miracle Tree: The Multiple Attributes of Moringa 172.

Guo, J.Y., Han, C.C. \& Liu, Y.M. (2010). A contemporary treatment Approach to both diabetes and depression by Cordyceps sinensus, rich in vanadium. Evid. Based Complement. Alternat. Med., 7(3), 387-389.

Hartwell, J.L. (1995). Plants used against Cancer. A Survey. Lloydia, 30-34.

Hossain, M.M., Miah, G., Ahamed, T. \& Sarmin, N.S. (2012). Study on allelopathic effect of Moringa oleifera on the growth and productivity of mungbean. International Journal of Agriculture and Crop Sciences (IJACS), 4(15), 1122-1128.

ICRAF (2001). Agroforestree (AFT) Database. The ICRAF Agroforestry Tree Database. http://www.icraf.cgiar.org/Sites/TreeDBS/aft.asp..Nairobi, Kenya.

Olofsdotter, M., Navarez, D. \& Rebulanan, M. (1997). Rice allelopathy -Where are we and how far can we get? In: The Brighton Crop Protection.

Phiri, C. \& Mbewe, D. N. (2009). Influence of Moringa leaf extracts on germination and seedling survival of three common legumes. Intl. Journal of Agriculture and Biology (in Press).

Phiri, C. (2010). Influence of Moringa oleifera leaf extracts on germination and early seedling development of major cereals. Agriculture and Biology J. of North America 1(5), 774-777.

Price, M.L. (1985). The Moringa Tree. ECHO, Durrance Rd., North Ft Myers FL 33917, USA.

Price, M.L. (2000). The Moringa Tree. Echo Technical Note. $<$ http://www.echotech.org/technical/technotes/moringabiomasa.pdf $>$. ECHO, North Ft. Myers, Florida, USA.

Sanker, K.B \& Rai, R. S. V. (1993). Allelopathic effects of a few tropical hard wood on olericultural crops. Indian Journal of Forestry 16, 246-249.

Suarez, M., J. M. Entenza, C. Doerries, E. Meyer, L. Bourquin, J. Sutherland, I. Marison, P. Moreillon \& N. Mermod. 2003. Expression of a plant-derived peptide harboring water-cleaning and antimicrobial activities. Biotechnology and Bioengineering 81,13-20.

Taiz, L. and Zeiger, E. 2006. Plant Physiology, Fourth ed. Sinauer Associates, Sunderland, MA, p764. USA.

Thurber, M. D. and Fahey, J. W. 2009. Adoption of Moringa oleifera to combat under-nutrition viewed through the lens of the "Diffusion of Innovations" theory. Ecology of Food and Nutrition 48, 212-225.

Zakaria, W. and Razzak, A. R. 1990. Effects of groundnut plant residues on germination and radical elongation of four crop species. Pertanika, 13, 297-302.

\section{Citation for this article (APA Style):}

Sarmin, N. S. (2014). Effect of Moringa oleifera on Germination and Growth of Triticum aestivum. Journal of Bioscience and Agriculture Research, 02(02), 59-69. Retrieved November 20, 2014, from http://www.journalbinet.com/current-issue-jbar-1.html 